Animal Production in Developing Countries

Occasional Publication No.16 - British Society of Animal Production 1993

edited by M. Gill, E. Owen, G. E. Pollett and T. L. J. Lawrence

\title{
Studies on the use of local animal food resources in the Republic of Kiribati
}

\author{
P. J. Thorne
}

Natural Resources Institute, Chatham Maritime, Kent ME4 4TB

\section{Introduction}

The Republic of Kiribati consists of numerous coral atolls spread over $3 \times 10^{6} \mathrm{~km}^{2}$ of the Central Pacific Ocean. Agricultural production in the atolls is severely limited by poor soils, high salinity and uncertain water supplies. A series of trials, conducted during 1989 and 1990 , evaluated different feeding strategies for pigs and poultry which were designed to optimize the use of the limited number of raw materials available locally. Trial results were related to the estimated demand for animal foods and the quantities of raw materials available in an attempt to assess their practical application.

\section{Material and methods}

Feeding trials with pigs

A range of dietary treatments compared foods based on local raw materials with imported control diets (Table 1).

\section{Feeding trials with poultry}

Similar approaches in poultry feeding were also studied.

\section{Results}

The locally produced pig foods allowed growth performances similar to those achieved with the

Table 1 Approaches to the use of local foods in Kiribati

Three basic approaches were used:

A. A compound food based on copra meal, waste fish dried onto copra meal and coconut log

B. The same local raw materials mixed with imported maize and wheat mill run

C. A simple combination of fresh fish, fresh coconut, rejected fruit and green fodders (an on-farm apoproach)
Table 2 Performance of growing pigs given local foodstuffs

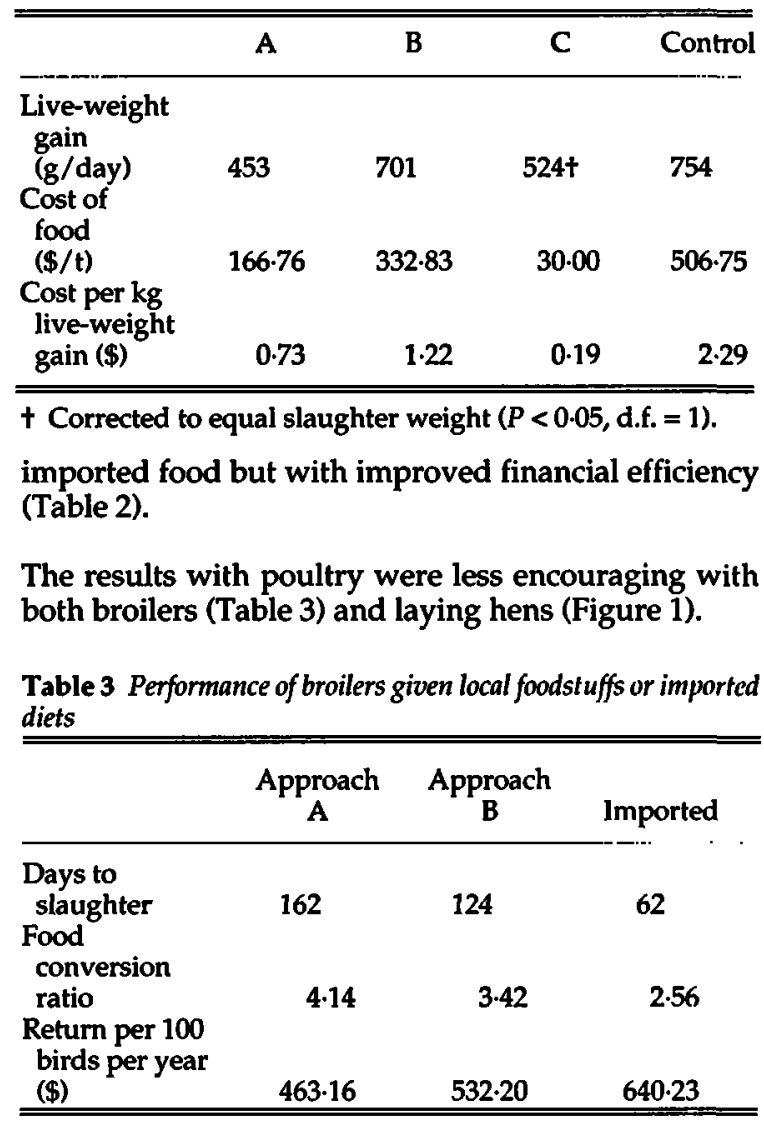

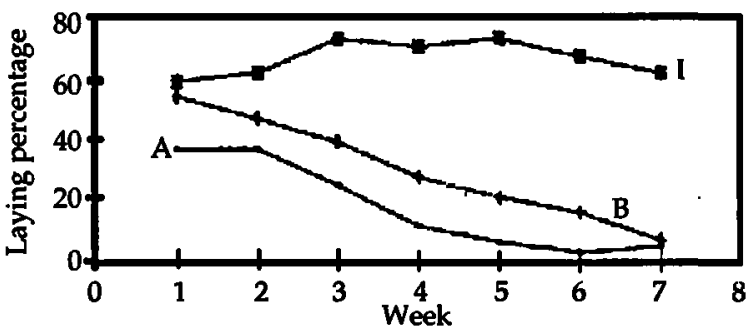

Figure 1 Layer trial - weekly laying percentages for approach A; approach B or imported (I). 
Table 4 Relationship between raw material supply and requirements for inclusion in foods ( $t$ /year)

\begin{tabular}{lccr}
\hline & $\begin{array}{c}\text { Pig } \\
\text { food }\end{array}$ & $\begin{array}{c}\text { Poultry } \\
\text { food }\end{array}$ & Total \\
\hline $\begin{array}{l}\text { Current demand } \\
\begin{array}{l}\text { Copra meal: } \\
\text { required } \\
\text { available }\end{array}\end{array}$ & 84.0 & 156.0 & 240.0 \\
$\begin{array}{l}\text { Fish waste: } \\
\text { required }\end{array}$ & 16.5 & 54.1 & 70.6 \\
available & 46.2 & 80.9 & $<100.0$ \\
\hline \hline
\end{tabular}

\section{Discussion}

Resolving technical and socio-economic constraints The relationships between the existing demand for compound food, the supply of raw materials locally and the animals' requirements for these raw materials, based on trial results, were evaluated (Table 4).

It was clear that the country's current requirements for compound foods could not be met entirely from local sources. Therefore, a strategy for providing an optimum combination of local and imported food for the country's livestock population is needed. As the performances of poultry given local foodstuffs were relatively poor, it is suggested that local foods should be directed preferentially towards pig feeding.

A number of further questions require consideration if the trial results are to be used successfully in the development of local food resources of Kiribati.

1. Would the labour requirement for food collection discourage the adoption of the on-farm approach to pig feeding?

2. What are the most viable options for small-scale commercial production of pig food in Kiribati?

3. Does the use of exotic hybrid broiler and layer strains constitute an appropriate technology in a country where food available locally cannot meet their exacting nutrient requirements?

4. To what extent would the use of the poultry foods tested improve the performance of the local chicken?

\section{Acknowledgements}

The work described was funded under the technical cooperation programme of the UK Government's Overseas Development Administration and conducted in collaboration with the Government of Kiribati, Ministry of Natural Resource Development. 